\title{
REVISTAMARACANAN
}

\section{Saberes e poderes no universo ibérico: discursos da cultura escrita na modernidade (Séculos XVI-XIX)}

\author{
Knowledge and powers in the iberian universe: discourses of written culture \\ in modernity (XVI- XIX)
}

Apresentação

Eliane Cristina Deckmann Fleck*

Universidade do Vale do Rio dos Sinos

São Leopoldo, Rio Grande do Sul, Brasil

Juliana Gesuelli Meirelles**

Pontifícia Universidade Católica de Campinas

Campinas, São Paulo, Brasil

Mauro Dillmann***

Universidade Federal de Pelotas

Pelotas, Rio Grande do Sul, Brasil

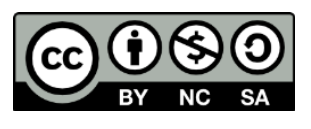

\begin{abstract}
* Professora titular da Universidade do Vale do Rio dos Sinos (UNISINOS). Doutora em História pela Pontifícia Universidade Católica do Rio Grande do Sul e Mestre e graduada pela UNISINOS. Integra a Rede de investigadores da Sociedade Internacional de Estudos Jesuíticos (SIEJ), com sede na EHESS, Paris (França) e a Red-HBP - Red de Historia de Brasil y Portugal -, com sede na UBA, Buenos Aires (Argentina), bem como a Comisión Permanente de las Jornadas Internacionales sobre las Misiones Jesuíticas. (efleck@unisinos.br)
\end{abstract}

(iD) https://orcid.org/0000-0002-7525-3606

(9) http://lattes.cnpq.br/8304454301957911

\footnotetext{
** Professora das Faculdades de História e Biblioteconomia da Pontifícia Universidade Católica de Campinas (PUC-CAMPINAS). Doutora e Mestre em História Política pela Universidade de Campinas. (jugmeirelles@gmail.com)

(iD) https://orcid.org/0000-0001-8722-6173 (9) http://lattes.cnpq.br/6609858966963474
}

*** Professor Adjunto no Departamento de História e no Programa de Pós-Graduação em História da Universidade Federal de Pelotas. Doutor e Mestre em História pela Universidade do Vale do Rio dos Sinos, (UNISINOS). Foi coordenador do Grupo de Trabalho História das Religiões e Religiosidades (Anpuh-RS) entre 2014 e 2018. Integra os seguintes Grupos de Pesquisa (CNPq): 'Imagens da Morte: a morte e o morrer no mundo Ibero-Americano', 'Paisagens Híbridas' e 'Heduca - História e Educação: textos, escritas e leituras'. (maurodillmann@hotmail.com)

(iD) https://orcid.org/0000-0002-8315-7788

(9) http://lattes.cnpq.br/5567003394621139 
A partir da década de 1990 houve um significativo crescimento de pesquisas no âmbito da historiografia nacional e internacional voltadas à compreensão da cultura escrita na modernidade. Essas investigações têm abarcado o período compreendido entre os séculos XVI e as independências americanas, no raiar do século XIX, e problematizado a produção, a circulação, o uso e a conservação de manuscritos e impressos vinculados aos seus usos políticos, sociais, religiosos, pedagógicos, culturais tanto na metrópole quanto no território colonial. Intelectuais como Roger Chartier, Robert Darnton, Antonio Castillo Goméz, Fernando Bouza e Diogo Ramada Curto têm contribuído, sobremaneira, para o avanço do conhecimento e da compreensão acerca da circulação de ideias através de seus trabalhos sobre a história do livro e da leitura e da história da cultura escrita global, que interligam manuscritos, impressos e oralidade.

Tais investidas têm considerado os domínios analíticos do discurso, das práticas e das representações, e compreendido a escrita como importante instrumento para o entendimento da difusão e apropriação de informações, saberes e poderes. As cartas dos administradores ultramarinos; o as múltiplas tipologias documentais do exercício do mando; os livros e peças de teatro censurados e proibidos de circular, assim como a estrutura da imprensa na metrópole e na colônia; o processo de escrita e tradução de obras científicas e literárias os documentos inquisitoriais; os papeis dos Tribunais de Relação; os escritos das ordens religiosas; os manuais e tratados que abrangiam os sentidos da vida pública e privada etc. são alguns exemplos da maciça produção escrita do período moderno.

Analisar estas fontes por meio da perspectiva da História Social da Cultura Escrita permite evidenciar a estreita relação entre o processo produtivo e a divulgação da informação e o que definimos como "os saberes e os poderes no universo ibérico", assim como a vinculação que se estabeleceu entre eles e a sustentação do poder monárquico ibérico, que aparece na formação de locus de cultura, de saber e de poder, tais como os reais arquivos e academias científicas. À luz dessas reflexões, pode-se ainda pensar o mundo colonial, a partir da expressão circulação planetária das coisas, proposta por Serge Gruzinski, uma vez que ela não apenas possibilitou a mobilidade das letras, como também promoveu nas quatro partes do mundo a difusão de informações e conhecimentos e o intercâmbio entre pessoas e culturas.

Os artigos que integram o dossiê constituem-se de resultados de investigações de caráter histórico que se dedicam a analisar aspectos caros à manutenção do mundo ibérico na modernidade e às experiências coloniais portuguesas e espanholas, entre elas, o trabalho missionário jesuítico e as relações mercantis. Neste sentido, aproximam-se não apenas porque se utilizam de documentos escritos (manuscritos ou impressos) como fonte de informação 
histórica, mas porque encaram a escrita como objeto de análise, como evidência de construção de interesses diversos (retóricos ou literários) presentes na produção (da autoria, da linguagem, da tipografia, etc.), nos suportes (materialidades dos textos, das imagens), nas significações (a depender dos usos, do escrever, ler, ver, ouvir), na divulgação (edições, aquisições, circulação, comércio, etc.), na recepção e na preservação desses textos.

O Dossiê é antecedido pela entrevista realizada com a Prof.a Dr.a Leila Algranti (Unicamp), na qual a historiadora discorre sobre sua trajetória e sobre sua produção historiográfica relativa à cultura escrita da Época Moderna. Uma das principais representantes da historiografia brasileira na temática, Algranti não só contribuiu para o avanço e o amadurecimento desse campo de estudo através de suas pesquisas individuais, como também por meio de um amplo e qualificado trabalho de orientação de pesquisas na pós-graduação ou, ainda, pela participação em projetos temáticos de grande impacto.

Com Ana Paula Megiani, a professora Algranti organizou a obra Império por escrito: formas de transmissão da cultura letrada no mundo ibérico (séculos XVI-XIX), ${ }^{1}$ a qual, ao longo desses últimos anos, conquistou incontornável importância no debate acerca dos usos, leituras e concepções das mais diversas fontes, temáticas e recortes de pesquisa, contribuindo decisivamente para a consolidação do Brasil no debate historiográfico internacional.

O Dossiê é composto por sete artigos, sendo que o primeiro intitula-se "Epos feminino e a trilogia épica de Soror Maria de Mesquita Pimentel (Paratextos e contextos)", e, nele, a autora Geise Kelly Teixeira da Silva apresenta uma abordagem sobre a produção épica de autoria feminina do período moderno, centrando-se particularmente sobre a trilogia épica de Soror Maria de Mesquita Pimentel: o Memorial da Infância de Cristo, o Memorial dos Milagres de Cristo e o Memorial da Paixão de Cristo. A partir de uma análise dos seus paratextos, Teixeira da Silva destaca alguns aspectos que permitem compreender como estes elementos periféricos ao texto (dedicatória, poemas laudatórios, licenças de impressão, prólogo) contribuem para a compreensão geral das obras, permitindo recuperar informações sobre o contexto de produção e de recepção das mesmas, bem como identificar os objetivos e estratégias que subjazem às intenções criadoras destes poemas em sede conventual feminina.

No segundo artigo, "Iconografia da Intolerância: impressos no combate à idolatria em regiões sob colonização hispânica", Jorge Victor de Araújo Souza \& Natalia de Souza Miranda defendem a ideia de que houve uma reinvenção da idolatria por parte de impressos publicados entre os séculos XVI e XVII, evidenciado, sobretudo, na presença de gravuras. A partir da análise de impressos e gravuras que integram uma coleção do acervo sobre a colonização da América da John Carter Brown Library, os autores discutem a importância dos conceitos de "idolatria" e "idoloclastia" para a compreensão das colonizações ibéricas, bem como procuram demonstrar a relação entre a performance da destruição de ídolos presente nas

\footnotetext{
${ }^{1}$ ALGRANTI, Leila Mezan \& MEGIANI, Ana Paula (Org.). Império por escrito: formas de transmissão da cultura letrada no mundo ibérico (séculos XVI-XIX). São Paulo: Alameda, 2009.
} 
imagens e a ideia de exorcismo da paisagem colonial, fundamental para o domínio dos territórios conquistados.

O terceiro artigo, "Impressões da guerra: as relações de sucesso lisboetas e madrilenas sobre a Restauração Portuguesa (1640 - 1668)", de Caroline Garcia Mendes, discute a publicação de impressos de notícias em Lisboa e em Madrid durante este período, discorrendo sobre os usos das relações de sucesso para informar sobre a guerra, enaltecer oficiais e grupos de soldados e atacar os inimigos através de relatos no intuito de desmoralizá-los. Além disso, aponta os principais recursos utilizados nos dois lados da fronteira para tratar do inimigo: se os castelhanos eram hereges e violentos nos impressos lisboetas, os papéis madrilenos publicavam que os portugueses estavam sendo enganados por um rebelde que precisava ser derrotado. De acordo com a autora, a quantidade de impressos produzidos em Lisboa foi bastante superior ao que foi publicado em Madrid, e neles pode-se encontrar ainda a participação de mulheres no conflito e menções a Bandarra e suas profecias.

Em "A construção da literatura histórica de Simão de Vasconcelos, SJ: entre o paradigma oriental e a busca por prestígio no século XVII", Camila Corrêa e Silva de Freitas se propõe a refletir sobre a cultura escrita do clero católico na época moderna vem destacando a relevância que a produção, a circulação e os diversos usos de textos, manuscritos e impressos, tiveram no desenvolvimento da missionação das ordens religiosas, dentro e fora da Europa, bem como a importância de se considerar o contexto histórico em que estes textos foram produzidos e utilizados. Dedica-se, ainda, à análise do processo de divulgação das obras históricas sobre a província do Brasil do jesuíta Simão de Vasconcelos entre as décadas de 1650 e 1660, levando em consideração três fatores contextuais importantes: a produção jesuítica de literatura histórica sobre as missões ultramarinas e sua publicização entre as décadas de 1550 e 1650 na Europa; os impactos da sua circulação nas dinâmicas internas da Companhia de Jesus; e as principais questões vividas pelos jesuítas da América portuguesa no período em que Vasconcelos elaborou seus textos. A partir da análise retórica e bibliográfica das obras do padre, bem como à luz do contexto das publicações jesuíticas missionárias e dos conflitos vividos pelos jesuítas do Brasil, a autora procura demonstrar como o religioso construiu um discurso histórico sobre a província brasílica se utilizando dos principais elementos de prestígio da época com vistas a atrair mais missionários e fortalecer a atuação da Ordem na América portuguesa.

No quinto artigo, intitulado "'Para os ensinar com esse método aos filhos": saberes indígenas e conversão jesuítica junto aos Kiriri nos sertões da América portuguesa (1668-1699)", Ane Luíse Mecenas Santos detém-se na segunda metade do século XVII, período em que se intensificou o povoamento do sertão da América portuguesa. De acordo com a autora, coube aos padres da Companhia de Jesus a tutela dos índios da nação Kiriri, que se encontravam na margem sul do Rio São Francisco, com vistas à implantação de novos aldeamentos. Durante este período, segundo a autora, foi produzido um significativo corpus documental, que versa sobre a solicitação de índios, traz notícias sobre as aldeias, descrições dos espaços e sobre a necessidade da elaboração de novos instrumentos que auxiliassem a comunicação e, para tanto, foram realizados estudos linguísticos, com o propósito de sistematizar e normatizar as línguas 
locais e tornar possível a comunicação e a pretendida conversão. No artigo, Mecenas Santos analisa detidamente duas obras que visaram normatizar a língua Kiriri, o Catecismo da Doutrina Christãa na Lingua Brasilica da Nação Kiriri e a Arte de Grammatica da Lingua Brasilica da naçam Kiriri, escritas pelo padre Ludovico Vicenzo Mamiani Della Rovere e utilizadas nas aldeias de Mirandela, Saco dos Morcegos, Natuba e Geru, na segunda metade do século XVII, com o objetivo de apresentar e de discutir as estratégias de conversão empregadas pelos missionários que atuaram junto aos Kiriri, bem como o processo de tradução cultural que o Catecismo e a Gramática evidenciam.

No sexto artigo, "Um comerciante lê livros: negócios e cultura escrita no Interior da América portuguesa", tomamos contato com os negócios e cultura escrita no interior da América portuguesa através da pesquisa realizada por Maria Aparecida de Menezes Borrego \& Jean Gomes de Souza, que nos mostram que, ao longo dos anos de 1730 e 1740, comerciantes e sertanistas atuantes nas minas de Cuiabá enviaram demandas de natureza diversa às autoridades locais e metropolitanas a fim de alcançarem vantagens no processo de ocupação do território. Os autores analisam um requerimento encabeçado pelo homem de negócios Luis Rodrigues Vilares, dirigido ao Senado da Câmara da Vila Real do Cuiabá em 1735, com vistas a obter autorização para o comércio de cavalos com os indígenas Guaykuru. Em um primeiro momento, os autores abordam as demandas dos colonos, materializadas no documento peticionário, por meio dos registros textuais e dos papéis que o compõem, acompanhando seus contextos de produção, recepção, circulação e guarda. Em seguida, a partir das obras mobilizadas no manuscrito, a atenção recai sobre a circulação de livros e ideias no interior da América portuguesa, a fim de identificarem as diferentes formas de apropriação dos conteúdos pelos requerentes. Segundo Menezes Borrego e Gomes de Souza, as solicitações dos comerciantes e seus encaminhamentos por parte dos funcionários régios evidenciam que o grupo mercantil soube se inserir na organização do Império lusitano, fazendo chegar às instâncias administrativas o conhecimento de seus interesses em razão do domínio sobre os meandros da cultura escrita.

O artigo "Notas sobre a História Trágico-Marítima (1735 - 1736), de Bernardo Gomes de Brito" encerra o dossiê. Nele, Cleber Vinícius do Amaral Felipe analisa os fundamentos retórico-históricos da coletânea História Trágico-Marítima, composta por doze relatos de naufrágio escritos entre os séculos XVI e XVII, que foi organizada por Bernardo Gomes de Brito e editada em dois tomos (1735-1736) sob amparo da Academia Real da História Portuguesa. O autor se propôs a compreender os sentidos do gênero histórico e a concepção de trágico nesta obra que se ampara em uma concepção providencialista de tempo, que desconhece as prerrogativas românticas, expressivas e psicologizantes que tendem a naturalizar e/ou autonomizar categorias como autor, literatura e pessimismo.

$\mathrm{Na}$ seção de artigos livres contamos com os trabalhos:""As vantagens e doçuras inapreciáveis da liberdade" Africanos livres, arrematantes particulares e o trabalho compulsório, século XIX" de Carlos Eduardo Moreira de Araújo, "Os privilégios do açúcar: a circulação do conhecimento e a institucionalização da ciência no Brasil (1833 - 1875)" de Rafael Dalysson 
dos Santos Souza \& Ramonilldes Alves Gomes, "A circulação de saberes e representações dos negros na cultura escrita de João Ribeiro na modernidade" de Cristina Ferreira de Assis \& Flávio Gonçalves dos Santos, "O Regionalismo e suas implicações literárias na contística de Bernardo Élis" de Fabianna Simão Bellizzi Carneiro, ""Periferias Renegadas" Memórias e resistências de uma Belford Roxo marcada pela violência urbana" de Marcelo Ribeiro Sales \& Diogo Silva do Nascimento e "A Memória da Ditadura Militar em disputa em vídeos e comentários no YouTube" de Lívia Diana Rocha Magalhães \& Eli Saraiva Santana.

Por fim, em "Crimes, justiças, agentes e instituições: temas de pesquisa em História Social" Avelino Pedro Nunes Bento da Silva resenha a coletânea História de crimes, justiça e instituições: fontes judiciais e agentes, organizada por Aguinaldo Rodrigues Gomes, Magda Nazaré Pereira da Costa, Adson Rodrigo Silva Pinheiro \& Raick de Jesus Souza.

Desejamos a todos uma boa leitura!

Os organizadores:

Eliane Cristina Deckmann Fleck Juliana Gesuelli Meirelles Mauro Dillmann 